\author{
MS39 P04 \\ Structural modifications in $\mathrm{V}_{2} \mathrm{O}_{5}$ xerogel films at \\ electrochromic coloring, alloying and annealing. \\ Liubov Lugovskaya Petrozavodsk State University pr. \\ Lenina 33, 185910 Petrozavodsk, Russia. \\ E-mail: liubovl@psu.karelia.ru
}

\section{Keywords: $\mathrm{V}_{2} \mathrm{O}_{5}$ xerogel, electrochromic colouring, $x$ - ray analysis}

In the given work $\mathrm{X}$-ray researches and construction of atomic structure models of $\mathrm{V}_{2} \mathrm{O}_{5}$ xerogel obtaining by zol-gel method are carry out, based on the complex analysis of curves of scattering intensity distribution. The structure and structural changes in $\mathrm{V}_{2} \mathrm{O}_{5} \quad \mathrm{nH}_{2} \mathrm{O}$ films, obtained from melt at various temperatures of quenching $\left(700,800,900\right.$ and $\left.1000^{\circ} \mathrm{C}\right)$ are investigated. It is shown, that the initial $\mathrm{V}_{2} \mathrm{O}_{5}$ films correspond to $\mathrm{V}_{2} \mathrm{O}_{5} * 1.6 \mathrm{H}_{2} \mathrm{O}$ xerogel, the crystallinity degree depends on quenching temperature. Differences in curves of scattering intensity for transmission and reflection geometries testifies to structural anisotropy of the xerogel films. Modification of films structure is investigated at their electrochromic colouring (internal electrochromic effect [1]) and the subsequent ageing. At coloring of the films, the interlayer spacing is increase in comparison with initial value. That caused by redistribution of ions $\mathrm{H}^{+}$inside a sample. At the ageing of samples, value of this interlayer spacing decreases in due course, reaching the size corresponding to an initial film in six days.

The curve of electronic density distributions D (r) and the characteristic of the short-range order (coordination numbers and coordination radiuses) are calculated by Warren - Finback method [2] and the analysis of atoms distribution is carried out. D (r) curves are identical for initial, colored and aged $\mathrm{V}_{2} \mathrm{O}_{5}$ zol-gel films, that testifies that the short-range order corresponding to an arrangement of atoms in a coordination polyhedron at coloring and ageing of films does not vary. Research of influence on $\mathrm{V}_{2} \mathrm{O}_{5} * \mathrm{nH}_{2} \mathrm{O}$ structure of $\mathrm{WO}_{3}$ impurity at various concentrations is carried out.

[1] Pergament A., Kazakova E., Stefanovich G. J.Phys.D: Appl.Phys. 2002. 35. 17. 2187-2197.

[2] Aleshina L. et all, J. Non-Cryst. Solids. 1986. 87. 350-358

\section{MS39 P05}

Extra modulations in thermoelectric misfit cobalt lamellar oxides. Dominique Grebille,Hervé Muguerra, Olivier Pérez, Emmanuel Guilmeau, Laboratoire CRISMAT, UMR CNRS 6508, ENSICAEN, Bd Maréchal Juin 14050 Caen cedex, France.

E-mail: dominique.grebille@ensicaen.fr

Keywords: aperiodic materials, thermoelectric materials, cobalt compounds
Misfit layered cobalt oxides have very interesting physical properties, such as thermoelectricity $(\mathrm{S}>100 \mu \mathrm{V} / \mathrm{K})$, directly related to the intrinsic non stoichiometry due to their lamellar aperiodic structure. A pseudohexagonal $\mathrm{CoO}_{2}$ layer is hole doped by the electronic transfer from different types of rocksalt layers [1] depending on the considered phase. The aperiodic misfit structure results from the mismatch between the cell parameters of both subsystems. A systematic and accurate structural investigation of this family shows first, that the $\mathrm{CoO}_{2}$ layers of these different oxides are very similar to each other, independently from the nature and the width of the rocksalt block, and second, that beside the misfit character of these complex structures, additional modulations are also present in several cases, which outlines the versatility of the rocksalt block. For example, the $\left[\mathrm{Bi}_{0.87} \mathrm{SrO}_{2}\right]_{2}\left[\mathrm{CoO}_{2}\right]_{1.82}$ compound was described in a $5 \mathrm{D}$ superspace approach with its intrinsic modulation mainly affecting the $\mathrm{BiO}$ layers [2]. Substituting $\mathrm{Ca}$ for $\mathrm{Sr}$, a new phase $\left[\mathrm{Bi}_{0.87} \mathrm{CaO}_{2}\right]_{2}\left[\mathrm{CoO}_{2}\right]_{1.69}$ with similar misfit features is obtained. An intrinsic modulation is also observed, but now in the same direction as the misfit aperiodicity, and with the same wave length. A 4D refinement has been successfully performed showing the lock in of the two aperiodicities on each other. Such extra modulations are not only specifically attached to Bi-O layers. The prototype phase $\left[\mathrm{Ca}_{2} \mathrm{CoO}_{3}\right]\left[\mathrm{CoO}_{2}\right]_{1.62}$ is known from powder diffraction experiments [3] or more recently from single crystal X-ray diffraction data [4]. In both cases, the central Co-O layer of the rocksalt block is characterized by a disorder described by a split atom model, both for Co and $\mathrm{O}$ species. A new commensurate modulated scheme has been observed and characterized perpendicularly to the misfit direction. The structure refinement from X-ray single crystal diffraction data involving both incommensurate-ness in the $\mathrm{b}$ direction of the misfit, and the commensurateness in the a and $\mathrm{c}$ directions has proved that this last modulation is related to an ordering of the Co-O layer, via a clustering of $\mathrm{Co}_{5} \mathrm{O}_{10}$ and $\mathrm{CoO}_{4}$ entities. Moreover, this ordering has been proved to be related to the small unexplained phase transition observed on the resistivity or magnetic susceptibility curves for this compound around $400 \mathrm{~K}[5,6]$. From these examples, it can be concluded that extra modulations are probably a spontaneous arrangement of the rocksalt layer to deal with the parameter mismatch of the misfit structure.

[1] Miyazaki, Y., Sol. State Ionicsl, 2004, 172, 463.

[2] Leligny, H.; Grebille, D.; Pérez, O.; Masset, A.C.; Hervieu, M.; Raveau, B., Acta Cryst B, 2000, 56, 173,

[3] Grebille, D.; Lambert, S.; Bourée, F.; Petříček, V., J. Appl. Cryst., 2004, 37, 823,

[4] Ling, C.D.; Aivazian, K.; Schmid, S.; Jensen, P., J. Sol. St. Chem. (2007) doi:101016/j.jssc.2007.02.016

[5] Masset, A.C.; Michel, C.; Maignan, A.; Hervieu, M.; Toulemonde, O.;Studer, F.; Raveau, B.; Hejtmanek, J., Phys. Rev. B 2000, 62, 166;

[6] Sugiyama, J.; Brewer, J.H.; Ansaldo, E.J.; Itahara, H.; Dohmae, K.; Seno, Y.; Xia, C.; Tani, T., Phys. Rev. B, 2003, 68, 134423. 